\begin{tabular}{cc} 
Derleme Makalesi / Review Article & Harran Tarım ve Gıda \\
Bilimleri Dergisi & \\
Geliş tarihi: 29.02.2016 & (2016) 20(2): 154-158 \\
\hline
\end{tabular}

\title{
Kırsal Göç ve Tarımsal Üretime Etkileri
}

\author{
Güneş EREN YALÇIN ${ }^{1 *}$, Fatma ÖCAL KARA ${ }^{2}$ \\ ${ }^{1}$ GAP Tarımsal Araştırma Enstitüsü Müdürlüğü, Tarım Ekonomisi Bölümü, Şanlıurfa \\ ${ }^{2}$ Harran Üniversitesi Ziraat Fakültesi Tarım Ekonomisi Bölümü, Şanlıurfa \\ *Sorumlu yazar: guneseren@hotmail.com
}

\begin{abstract}
Öz
Insanların çeşitli nedenlerle yaşadıkları coğrafi alanı terk edip başka yerlere yerleşerek yaşamlarını devam ettirmeleri göç olarak ifade edilmektedir. Kırsal göç ise, kırsal alanlarda yaşayan insanların yeni yaşam alanlarına taşınması olup, bu hareket daha çok kırdan kente doğru olmaktadır. Türkiye'de kırdan kente göç, 1950'li yıllarda sanayi devrimi ile başlamış olup hala devam etmektedir. Kırsal alanda yaşayan nüfusun büyük bir bölümü tarımsal faaliyet ile geçimlerini sağlamaktadırlar. Artan nüfus ile tarımdan sağlanan gelirin yetersiz kalması, tarım arazilerinin çeşitli nedenlerle parçalanmasıyla tarım işletmelerinin düşük gelirli küçük işletmelere dönüşmesi, tarımsal üretimde yeni gelişmeler ile makine kullanımının artmasıyla iş gücüne olan talebin azalması gibi özellikle ekonomik kökenli nedenlerle köyden kente göç gerçekleşmektedir. Yaşanan göç, tarımsal üretimde çalışacak genç işgücünün azalması, terk edilen arazilerin atı şekilde kalması, tarımda üretim ve verimin düşmesi, kırsal yoksulluğun artması gibi birçok sorunu da beraberinde getirmektedir. Bu çalışmada, daha önce yapılmış olan çalışmalar ve çeşitli kurumlara ait istatistiklerden yararlanılarak kırdan kente göç, nedenleri ve tarımsal üretime etkileri araştırımış olup, sorunların çözümüne yönelik öneriler getirilmiştir.
\end{abstract}

Anahtar kelimeler: Göç, Kırsal göç, Nüfus, Kent

\section{Rural Migration and Effects on Agricultural Production}

\begin{abstract}
Migration is expressed that people go on their life on other places by leaving their geographical area they live for various reasons. On the other side, rural migration is that people living in rural areas move to new habitats, and generally this movement is to the city from rural areas. Rural-urban migration in Turkey started with the industrial revolution in the 1950s and still remains. A large proportion of the population living in rural areas has get on with agricultural activities as a daily bread. Migration from villages to cities is mainly realized for reasons of economic origin like inadequacy of the revenues earned from agriculture because of growing population, conversion to low incomes small businesses of agricultural holdings with cleavage of lands the reduction of the demand for labor by increasing the use of the machine with the new developments in agricultural production. Experienced migration brings along reduction of the young labor force to work in agricultural production, the remains of lands people leave, the drop in agricultural production and productivity, many problems such as the increase in rural poverty. In this study, it has been brought proposals for solution of problems and investigated causes and effects of rural urban migration on agricultural production with studies conducted before and by using statics from various institutions.
\end{abstract}

Key Words: Migration, Rural migration, Population, City. 
Giriş

Ekonomik, siyasi, sosyal, kültürel, dini vb. nedenler ile insanların bulundukları yerden ayrılıp, coğrafi olarak yer değiştirmeleri göç olarak adlandırılmaktadır. Kırsal göç ise, kırsal alanlarda yaşayan insanların yeni yaşam alanlarına taşınması olup, bu hareket daha çok kırdan kente doğru olmaktadır. Göçü, iç göçler ve dış göçler olarak 2 kısma ayırmak mümkündür. İç göçler, aynı ülke sınırları içerisinde, bir bölgeden başka bir bölgeye, bir şehirden başka bir şehre veya kırsaldan şehre doğru gerçekleşen göç hareketidir. İç göçler, mevsimlik göçler, sürekli göçler, emek göçleri, zorunlu-gönüllü göçler olarak sınıflandırılmaktadır.

Insanların her yıl belirli aylar içerisinde bulundukları ortamdan başka bir ortama çalışmak, gezmek ya da dinlenmek için bir müddetliğine gitmeleri olayına mevsimlik göç, yaşadıkları yerden başka bir yere, temelli yerleşmek üzere gitmelerine ise sürekli göç denilmektedir. Emek göçleri, tayin nedeniyle yapılan göçler ve işgücü göçleri olarak gerçekleşmektedir. Zorunlu göçler, insanların isteğine bırakılmadan, devlet tarafından bazı olaylar ve durumlar karşısında mecburi olarak yaptırılan göçlerdir. Gönüllü göçler ise, hiçbir baskıya maruz kalmadan insanların kendi tercihleri doğrultusunda yaptıkları göçlerdir (Koçak ve Terzi, 2012).

Dış göçler ise, insanların ekonomik, kültürel, siyasi vb. sebeplerle gönüllü veya zorunlu olarak bulundukları ülkeden ayrılıp başka bir ülkeye göç etmesi olarak tanımlanmaktadır.

Bu çalışmanın esas konusu kırsal göç olup, çalışma kapsamında kırsal göçün Türkiye'de ne zaman başladığı, göçü doğuran etmenlerin neler olduğu, kırsal göçün tarımsal üretim üzerindeki etkileri daha önce yapılmış olan çalışmalar incelerek tespit edilmeye çalışılmıştır.

\section{Materyal ve Yöntem}

Bu çalışmada; daha önce konu ile ilgili yapılmış akademik çalışmalar ile çeşitli kurum ve kuruluşlara ait istatistikler derlenerek, kırsal göçün nedenleri ve tarımsal üretime etkileri belirtilmeye çalışımıştır.

\section{Araştırma Bulguları ve Tartışma}

Çizelge 1'de 1927-2015 yılları arasında Türkiye'de genel nüfus, kent ve köy nüfusu incelendiğinde, 1927-1950 yılları arasında kent nüfusundaki artış önemsenecek boyutta olmamıştır. 1950 yılında gerçekleşen sanayi devrimi, Türkiye'de de bir dönüm noktası olmuş ve kırdan kente göçler başlamıştır. Illk nüfus sayımının yapıldığı 1927 yılında toplam nüfusun \%76'sı kırsal alanda yaşarken, bu oran sanayi devrimi ile giderek azalmaya başlamış 1960 yılında \%68'e, 1985 yılında \%47'ye, 2000 yılında \%35'e, 2015 yılında ise \%7,9’a düşmüştür. 1985 yılına kadar köy nüfusu kent nüfusundan fazla iken, bu yıldan sonra köy nüfusu kent nüfusunun sürekli olarak altında seyretmiştir.

\section{Kırsal Göçün Ekonomik Etmenleri}

Kırsal alandan kente doğru gerçekleşen göç hareketinin en büyük nedeni ekonomik etmenlerdir. Sanayi devrimi ile kırsal nüfusun geçimini sağladığı tarım sektörüne yavaş yavaş makinenin girmesi tarımda işgücü intiyacını azaltmış ve bu iş gücünün yeni iş arayışları ile şehirlere göçü başlamıştır. Tarım arazilerinin çeşitli nedenlerle parçalanması sonucu, tarım işletmelerinin çok parçalı, küçük ölçekli işletmelere dönüşmesi, çiftçinin geçimini sağlayacak yeterli geliri elde edememesi köyden kente doğru yaşanan göçün ekonomik nedenleridir. Kırsal nüfusun 
artması ile artan nüfusun yeni istihdam kaynakları araması, teknolojik gelişmeler ile şehirlerde artan istihdam olanakları göçü etkileyen etmenler arasındadır. Tarımsal üreticinin örgütlenmelerinde ki yetersizliklerden dolayı piyasada fiyata etkili olamamaları üreticinin tarımsal üretimden uzaklaşıp göç etmesine sebep olmaktadır.

Bilindiği üzere tarımsal üretim doğal koşullara bağııdır ve risk ile belirsizlik diğer sektörlere göre daha fazladır. Diğer taraftan sermayenin devri de yavaş gerçekleşmektedir. Bu gibi etmenlerde küçük ölçekli, az gelirli işletmeleri tarımsal üretimi bıraktırıp göçe itmiştir.

Bu dönemdeki kırsal göçler sadece kırsal alanlardaki işsizlik ve fakirlikten değil, aynı zamanda kırsal alanlarda önemli gelir sağlayan büyük toprak sahiplerinin göç ederek yatırımlarını sanayi şehirlerine yapmasıyla da gerçekleşmiştir (Gürbüz ve Karabulut, 2008).

Özellikle küçük işletmelerden oluşan Türk tarım yapısında, üretim girdilerinin küçük işletmelerde birim maliyetleri artırması buna karşılık piyasada oluşan düşük ürün fiyatları, desteklemelerden yararlanmada yaşanılan sıkıntılar, küçük işletmeler için cazip olmayan koşullara sahip tarımsal krediler tarımı itici hale getirmiş ve nihayetinde çiftçiler göç etmek zorunda kalmışlardır.

Diğer taraftan, 1950'li yıllardan itibaren karayolu, baraj ve liman gibi büyük projeler sonucu kamulaştırmalar yapılmıştır. Özellikle baraj ve sulama projelerinde baraj gölü ve koruma havzası nedeniyle ilçe ve köyler arazileri ile birlikte istimlak edilmiştir. Bu bölgelerdeki halk ya yeni iskân bölgelerine ya da tercih ettikleri yerleşim birimlerine göç etmek zorunda kalmışlardır (Pazarlıoğlu, 2007).

Çizelge 1. Türkiye'de Yıllar Itibariyle Toplam Nüfus, Kent ve Köy Nüfusu

Tabl:1 Total population, urban and village population of Turkey in years

\begin{tabular}{|c|c|c|c|c|c|}
\hline Yıllar & Toplam Nüfus & Kent Nüfusu & Kent (\%) & Köy Nüfusu & Köy (\%) \\
\hline 1927 & 13.648 .270 & 3.305 .879 & 24,2 & 10.342 .391 & 75,8 \\
\hline 1935 & 16.158 .018 & 3.802 .642 & 23,5 & 12.355 .376 & 76,5 \\
\hline 1940 & 17.820 .950 & 4.346 .249 & 24,4 & 13.474 .701 & 75,6 \\
\hline 1945 & 18.790 .174 & 4.687 .102 & 24,9 & 14.103 .072 & 75,1 \\
\hline 1950 & 20.947 .188 & 5.244 .337 & 25,0 & 15.702 .851 & 75,0 \\
\hline 1955 & 24.064 .763 & 6.927 .343 & 28,8 & 17.137 .420 & 71,2 \\
\hline 1960 & 27.754 .820 & 8.859 .731 & 31,9 & 18.895 .089 & 68,1 \\
\hline 1965 & 31.391 .421 & 10.805 .817 & 34,4 & 20.585 .604 & 65,6 \\
\hline 1970 & 35.605 .176 & 13.691 .101 & 38,5 & 21.914 .075 & 61,5 \\
\hline 1975 & 40.347 .719 & 16.869 .068 & 41,8 & 23.478 .651 & 58,2 \\
\hline 1980 & 44.736 .957 & 19.645 .007 & 43,9 & 25.091 .950 & 56,1 \\
\hline 1985 & 50.664 .458 & 26.865 .757 & 53,0 & 23.798 .701 & 47,0 \\
\hline 1990 & 56.473 .035 & 33.326 .351 & 59,0 & 23.146 .684 & 41,0 \\
\hline 2000 & 67.803 .927 & 44.006 .274 & 64,9 & 23.797 .653 & 35,1 \\
\hline 2007 & 70.586 .256 & 49.747 .859 & 70,5 & 20.838 .397 & 29,5 \\
\hline 2008 & 71.517 .100 & 53.611 .723 & 75,0 & 17.905 .377 & 25,0 \\
\hline 2009 & 72.561 .312 & 54.807 .219 & 75,5 & 17.754 .093 & 24,5 \\
\hline 2010 & 73.722 .988 & 56.222 .356 & 76,3 & 17.500 .632 & 23,7 \\
\hline 2011 & 74.724 .269 & 57.385 .706 & 76,8 & 17.338 .563 & 23,2 \\
\hline 2012 & 75.627 .384 & 58.448 .431 & 77,3 & 17.178 .953 & 22,7 \\
\hline 2013 & 76.667 .864 & 70.034 .413 & 91,3 & 6.633 .451 & 8,7 \\
\hline 2014 & 77.695 .904 & 71.286 .182 & 91,8 & 6.409 .722 & 8,2 \\
\hline 2015 & 78.741 .053 & 72.523 .134 & 92,1 & 6.217 .919 & 7,9 \\
\hline
\end{tabular}

Kaynak: (Anonim, 2016) 


\section{Kırsal Göçün Sosyal Etmenleri}

Kırsal alandan yaşanan göçün temel etkeni ekonomik sebepler olsa da elbette göçü tetikleyen başka unsurlarda bulunmaktadır.

- Doğu ve Güneydoğu Bölgeleri'n de yaşanan terör olayları burada yaşayan halkın güvenlik nedeniyle başka yerlere göç etmesine sebep olmuştur.

- Doğal afetler ve özellikle de Türkiye'de son yıllarda yaşanmış olan depremlerde, orada yaşayanların ailelerini kaybetmeleri, evlerinin iş yerlerinin kullanılamaz hale gelmesi gibi nedenler başka yerlere göçü doğurmuştur.

- Kırsal alanlarda şehirlere kıyasla eğitim ve sağlık imkanlarının oldukça yetersiz olması kırsalda yaşayan halk için şehirleri cazip kılmış ve göçü tetiklemiştir.

- Ulaşım, iletişim, elektrik, su gibi hizmetlerin bazı kırsal bölgelere günümüzde dahi hala ulaşmamış olması göçe sebep olan bir başka etmendir.

- Kırsal alanlarda bulunmayan sosyal imkanların, şehirler de fazla oluşu şehir yaşantısı daha çekici hale getirmiştir.

- Şehirlerde yaşayan akraba, dost, arkadaş gibi kişilerle bir arada olma isteği de göçe sebep olan bir başka durumdur.

Türkiye geneline bakıldığında köyden kente göçün özellikle Doğu, Güneydoğu ve Karadeniz Bölgeleri'nden ülkenin Batı bölgelerine doğru olduğu görülmektedir. Bu göçler İstanbul, Ankara, İzmir ve Bursa başta olmak üzere batı bölgelerindeki kentlere yoğunlaşmaktadır (Güreşçi, 2012). Diğer taraftan göç edilen yerlerdeki artan nüfus ile işsizlik sorunu buralarda da devam etmekte, göç eden vasıfsız işgücü istihdam sorunu yaşamaktadır. Ekonomik sorunları devam eden bu nüfus, kentlerde mülkiyeti başkalarına ait olan arazilere yasal olmayan şekilde gecekondu olarak tabir edilen binalar yapıp buralarda yaşamaya başlamışlardır. Yaşadıkları bu bölgeler eğitim, sağlık, ulaşım, altyapı gibi sorunların olduğu alanlardır. Köylerden göç eden nüfus hem kent yaşamına uymada zorlanmış ve kendi yaşam şekillerini buralarda sürdürmeye çalışmış hem de kentliler tarafından dışlanmış ve kabul görmemişlerdir.

Göç sadece kentsel alanlar için bir sorun olarak algılansa da, kırsal alanlarda yaşayanlar içinde önemli bir sorundur. Diyarbakır Çayönü'n de yapılan bir araştırmaya göre; katılımcıların köyün sorunlarını derecelendirmeleri istendiğinde, göç olayını $\% 88,8$ gibi yüksek bir oranda sorun olarak algılamadıkları görülmüştür. Aynı çalışmada genç işgücü olmamasını sorun olarak algılamayanların oranı \% 57,7 olup bu sorunu çok önemli bir sorun olarak algılayanların oranı \% 29,6 olarak tespit edilmiştir (Akın, S. Ve ark., 2015). Kırsal alanlarda yaşayan kesimin büyük kısmı geçimini tarımsal üretim ile sağlamaktadır ve kırsaldan yaşanan göçün en büyük etkisi de tarım üzerine olacaktır. Bu etkiler;

- Yaşanan göç ile Türkiye tarım ülkesi olma özelliğini gün geçtikçe kaybetmektedir.

- Dünya da giderek artan tarım nüfusu Türkiye'de ise düşüş göstermektedir.

- Göç eden nüfusla beraber tarımsal üretimde meydana gelen azalma Türkiye'de bugün birçok ürünün ithal edilmesine sebep olmaktadır.

- Özellikle tarımın geleceği olan genç nüfusun göç ediyor olması ilerleyen zamanlar için büyük tehdit oluşturmaktadır.

- Üretimden vazgeçilmesi ile boşalan araziler amaç dışı kullanılarak doğal kaynaklar hızla yok olmaktadır.

- Tarımsal üretimden uzaklaşma ile gıda güvencesi birçok üründe tehlike altına girecek ülke nüfusunun gıdaya ulaşması güçleşecektir.

- Kırsal göç sonucu tarımsal alanlarda kaynak israfı olacak, boş ve bakımsız araziler erozyona maruz kalacaktır (Güreşçi, 2009). 


\section{Sonuçlar}

Kırsal nüfusun geçim kaynağı çoğunlukla tarımsal üretimdir. Tarım arazilerinin çeşitli nedenlerle parçalanması, Türkiye'de üreticinin küçük ölçekli, dar gelirli işletme yapısına sahip olması, düşük seyreden ürün fiyatları buna karşı girdi fiyatlarının yüksek olması gibi tarım ağırlıklı faktörler başta olmak üzere birçok neden kırsal nüfusun kentlere göç etmesine sebep olmaktadır.

Özellikle tarımsal üretimi etkileyecek yönde önerilerle kırsal göçü azaltacak etmenlerin neler olabileceği aşağıda sıralanmaktadır.

- Miras yolu ile arazi parçalanması engellenmelidir.

- Köylünün temel geçim kaynağını oluşturan tarımsal üretimi destekleyecek politikalar karar mekanizmaları tarafından planlanmalıdır.

- Aile geçimini bile karşılamakta zorlanan ve toplam tarım nüfusunun büyük kısmını oluşturan küçük işletmeleri destekleyici politikalar geliştirilmelidir.

- Tarımsal krediler çiftçilerin faydalanabileceği uygun koşullara getirilmelidir.

- Girdi ve ürün fiyatları arasındaki dengesizlik giderilmelidir.

- Çiftçilerin geleneksel üretim metotlarından uzaklaştırılıp, yüksek verim ve geliri hedefleyen yeni teknik ve metotlarla tanıştırılması ve dolayısıyla yayım hizmetlerinin arttırılması gerekmektedir.

- Çiftçilerin yeni ürün çeşitlerine yer verebilmeleri için yönlendirilmeleri gerekmektedir.

- Kırsal alanlarda tarıma dayalı sanayi yatırımları geliştirilmelidir.

- Göçü tetikleyen sağlık, eğitim, güvenlik, ulaşım, altyapı ve benzeri sorunlar giderilmelidir.
- Köylerdeki vasıfsız iş gücüne istihdam olanakları sağlanmalıdır.

\section{Kaynaklar}

Akın, S., Altan, M., K., Kara, Ö., F., Atsan, T., 2015. The Potential of Rural Tourısm in Turkey: The Case Study of Cayonu. Pakistan Journal of Agricultural Sciences, 52(3):853859, Faisalabad, Pakistan.

Anonim, 2016. www.tuik.gov.tr

Gürbüz, M., Karabulut, M., 2008. Kırsal Göçler ile Sosyo-Ekonomik Özellikler Arasındaki iliş̧kilerin Analizi. Türk Coğrafya Dergisi, (50):37-60, İstanbul.

Güreşçi, E., 2009. Kırsal Göç ve Tarım Politikası Arasındaki İlişki. Muğla Üniversitesi, Sosyal Bilimler Enstitüsü Dergisi, (22):51-67, Muğla.

Güreşçi, E., 2012. Türkiye'nin Köyden Kente Göç Sorunu. Gümüşhane Üniversitesi, Sosyal Bilimler Elektronik Dergisi, (6):41-55, Gümüşhane.

Koçak, Y., Terzi, E., 2012. Türkiye'de Göç Olgusu, Göç Edenlerin Kentlere Olan Etkileri ve Çözüm Önerileri. Kafkas Üniversitesi, İktisadi ve İdari Bilimler Fakültesi Dergisi, 3(3):163-184, Kars.

Pazarlıoğlu, V., 2007. İzmir Örneğinde İç Göçün Ekonometrik Analizi. Celal Bayar Üniversitesi, İdari ve İktisadi Bilimler Fakültesi, Yönetim ve Ekonomi Dergisi, 14(1):121-135, Manisa. 